\section{Stimulus meaning as a variable in dichotic listening}

\author{
MARYO GARD WHITMORE* \\ Department of Administrative Sciences \\ Yale University, New Haven, Conn. 06520
}

Ss were given no instructions or were told to alternate attention during the dichotic presentation of sequential word pairs. Without instructions, Ss tended to respond according to Broadbent's $(1954,1958)$ model; when told to alternate attention between channels, Ss were able to do so, according to Emmerich et al's (1965) model.

Broadbent's model (1952, 1954, 1958) of dichotic listening posits that when pairs of digits in series are dichotically presented, Ss will report them in the fashion "LLLRRR" rather than in the actual temporal order of presentation (LRLRLR). Based partially upon this data, he concluded that at high rates of information, a short-term "storage" mechanism is employed, allowing Ss' perceptual systems to deal first with the inputs to one channel and then to analyze inputs to the other; Ss are unable to alternate attention.

Emmerich, Goldenbaum, Hayden, Hoffman, \& Treffts (1965) challenge Broadbent's model; they feel that when "material facilitating meaningful associations" is used, Ss will use a "relatively permanent memory system [p. 433]." Using one-syllable words, unordered or in sequence, instead of Broadbent's digits, they presented stimuli dichotically to Ss, informing Ss that if they alternated their attention, they might hear a sentence. Their hypothesis was confirmed when Ss made fewer errors in the "sentence" condition and when told to alternate attention regardless of word order. Emmerich et al conclude that "meaning" elicits a different response pattern from Broadbent's and that words, inherently more "meaningful" than digits, facilitate response, since $\mathrm{Ss}$ made fewer errors when told to alternate attention than when listening by channel.

The present study represents an attempt to replicate Emmerich et al's findings, with one major modification. Ss had been told to alternate attention to hear a sentence, but the conclusions claim that inherent stimulus "meaning" enabled them to alternate. Thus, Emmerich et al failed to distinguish clearly between "meaning" and "instruction."

If it is true, as they suggest, that in the presence of "meaning" Ss will alternate attention between channels, then Ss given neutral instructions

*I wish to thank Dr. Robert Davidon and Dr. Robert Sobel for their help and criticisms of this study. ought to perform as well as Ss instructed to alternate. If, however, the effect is due to instruction, then Ss told to switch should perform differently from $S s$ in the neutral condition; the differences would presumably be in the direction of ordering the words to make a sentence sequence.

\section{METHOD}

Thirteen Ss were used; all were female undergraduates with normal hearing, and all were naive about dichotic listening experiments. Due to difficulties in obtaining large numbers of Ss, each girl served as her own control.

The stimulus material was recorded on a Sony 600 stereo tape recorder and was presented dichotically to the Ss via headphones. Technical problems necessitated using different voices for each channel; the attempt was made, however, to use two female voices as identical as possible, and volume levels were adjusted to coincide. (Emmerich et al, incidentally, introduced here a potential source of bias, using a male voice on one channel and a female voice on the other.) The material consisted of 10 groups of six one-syllable words, arranged as follows:

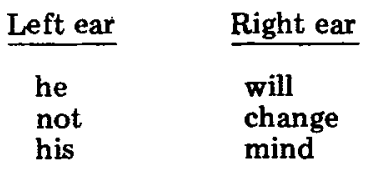

Use of " $a$," "the," and "and" was avoided to minimize ambiguity. One-half second elapsed between the onset of one word pair and the next; $13 \mathrm{sec}$ were allotted between word groups for Ss' oral report. (It was felt that Emmerich et al's use of written report was another possible biasing factor.)

Each S was presented five groups of stimuli with the neutral instructions ("report as many of the words you hear as you can") and then five groups with test instructions ("for each pair of words, listen first to the words in your left ear, then in your right, and report what you hear"). The instructions were presented on the tape recorder, and, to eliminate any preconceived "set," the neutral instructions also indicated that $S$ might hear a word in her left ear, right ear, or both ears. Finally, to avoid any possible order effect, the sentences with neutral instructions for half of the $\mathrm{Ss}$ were used as the test sentences for the other half, and vice versa.

It was hypothesized that Ss with neutral instructions would demonstrate Broadbent's order effect, and that with test instructions, they would respond according to sentence order.

\section{RESULTS}

It was decided to treat the responses in terms of sequential pairs of words. In the sample sentence:

$\begin{array}{ll}\text { he } & \text { will } \\ \text { not } & \text { change } \\ \text { his } & \text { mind }\end{array}$

a response of "he, not, his, will, change, mind" would follow Broadbent's model; "he, will, not, change, his, mind" would favor Emmerich et al's model. The score assigned to any response depended upon the number of word pairs falling into either category. Thus, "he, not," "not, his," "will, change," and "change, mind" are the only ear order pairs of the sample; a perfect score is 4. "He, will," "will, not," "not, change," "change, his," and "his, mind" are the "meaning" or alternating pairs, for a perfect score of 5. A sequence falling in neither category ("he, change") would not be tallied. Two Wilcoxon signed-rank tests can be performed, one for ear order, the other for meaning, comparing the change in response between conditions for each $\mathrm{S}$ (see Table 1).

\section{DISCUSSION}

The results are highly significant in the predicted directions. Broadbent's model has not been disproved, and the criticisms made of Emmerich et al's experiment are apparently justified. "Meaning" is not an inherently recognizable property of a group of stimulus words in such a situation, as Emmerich et al would have it, but rather is dependent upon context. Here, context was provided by the instructions to alternate attention. Ss have the ability to listen either by ear channel or by alternating attention between channels; perhaps Gray \& Wedderburn (1960) are correct in their supposition that with no organizational cues the Ss will pick channel listening as the optimal strategy for obtaining the most information.

If it is true that in some sense 
Table 1

Comparison of Responses of $S_{s}$ in the Ear-Order and Meaning-Order Conditions*

\begin{tabular}{|c|c|c|c|c|c|c|c|c|c|}
\hline \multicolumn{5}{|c|}{ Ear Pairs } & \multicolumn{5}{|c|}{ Meaning Pairs } \\
\hline $\mathbf{s}$ & Neutral & Test & D & Rank & $\mathbf{S}$ & Neutral & Test & D & Rank \\
\hline 1 & 9 & 4 & 5 & 6 & 1 & 4 & 8 & -4 & 7 \\
\hline 2 & 5 & 5 & 0 & - & 2 & 0 & 7 & -7 & 10 \\
\hline 3 & 7 & 3 & 4 & 3 & $\overline{3}$ & 8 & 7 & 1 & 2 \\
\hline 4 & 3 & 3 & $\mathbf{0}$ & - & 4 & 3 & 8 & -5 & 9 \\
\hline 5 & 5 & 0 & 5 & 6 & 5 & 1 & 3 & -2 & 4 \\
\hline 6 & 7 & 2 & 5 & 6 & 6 & 6 & 9 & $-\mathbf{3}$ & 5 \\
\hline 7 & 8 & $\mathbf{0}$ & 8 & 9 & 7 & 10 & 23 & -13 & 11 \\
\hline 8 & 8 & 2 & 6 & 8 & 8 & 2 & 6 & -4 & 7 \\
\hline $\mathbf{9}$ & 1 & $\overline{3}$ & -2 & 1 & 9 & 3 & 7 & -4 & 7 \\
\hline 10 & 12 & 8 & 4 & 3 & 10 & 2 & 0 & 2 & 1 \\
\hline 11 & 6 & 2 & 4 & $\mathbf{3}$ & 11 & 9 & 10 & -1 & 3 \\
\hline 12 & 11 & 0 & 11 & 11 & 12 & 2 & 22 & -20 & 13 \\
\hline 13 & 12 & 2 & 10 & 10 & 13 & 2 & 16 & -14 & 12 \\
\hline \multicolumn{5}{|c|}{$\mathrm{T}=1, \mathrm{p}<.005$ (one-tailed tests) } & \multicolumn{5}{|c|}{$\mathrm{T}=3, \mathrm{p}<.005$ (one-tailed tests) } \\
\hline & & & & & & & & & \\
\hline
\end{tabular}

*Wilcoxon signed rank tests for matched samples

context allows Ss to choose an organizational strategy, a qualification of Broadbent's model is implied. Broadbent's experiment with digits might be performed using the method of this experiment, e.g.,

$\begin{array}{rr}\text { Left ear } & \text { Right ear } \\ 2 & 4 \\ 6 & 8 \\ 10 & 12\end{array}$

This is obviously a common ("meaningful") sequence if listened to in alternation. If the results are the same as those obtained here (i.e., if Ss given no specific instructions respond according to channel and if Ss told to alternate ears demonstrate that they could do so), then not only would this suggest that Broadbent's original model holds only when no context is present, but also that the variable of speed of stimulus arrival may not be as absolute as he suggests. He posits, for instance $(1954,1958)$, that at high rates of information-presentation $\mathrm{S}_{\mathrm{s}}$ will respond by channel, whereas at
REFERENCES

BROADBENT, D. Listening to one of two synchronous messages. Journal of Experimental Psychology, 1952, 44, 51-55.

BROADBENT, D. The role of auditory localization in attention and memory span. Journal of Experimental Psychology, 1954, 47, 191-196.

BROADBENT, D. Perception and communication. London: Pergamon Press, 1958.

DEUTSCH, J, \& DEUTSCH, D. Attention: Some theoretical considerations. Psychological Review 1963, 70, 80-90.

DEUTSCH, J., \& DEUTSCH, D. Comments on "Selective listing: Perception or response?" Quarterly Journal of Experimental Psychology, 1967, 19. 262-263.

EMMERICH, D., GOLDENBAUM, D., HAY DEN, D., HOFFMAN, L., \& TREFFTS, J. Meaningfulness as a variable in dichotic hearing. Journal of Experimental Psychology, 1965, 69. 433-436.

GRAY, J., \& WEDDERBURN, A. Grouping strategies with simultaneous stimuli. Quarterly Journal of Experimental Psychology, 1960, 12, 180-184.

MILLER, G., \& SELFRIDGE, J. Verbal context and the recall of meaningful material American Journal of Psychology, 1950, 63, 176-186.

MORAY, N. Attention in dichotic listening: Affective cues and the influence of instructions. Quarterly Journal of Experimental Psychology, 1959, 11, 56-60.

MORAY, N. Broadbent's filter theory: Postulate $H$ and the problem of switching time. Quarterly Journal of Experimental Psychology, 1960, 12, 214-220.

REYNOLDS, D. Effects of double stimulation: Temporary inhibition of response. Psychological Bulletin, 1964. 62, 333-347.

SIEGEL, S. Non-parametric statistics for the behovioral sciences. New York: McGraw-Hill, 1956.

TREISMAN, A. Contextual cues in selective listening. Quarterly Journal of Experimental Psychology, 1960, 12. 242-248.

TREISMAN, A. Reply to comments on "Selective listening: Perception or response?" Quarterly Journal of Experimental Psychology, 1967, 19, 364-366.

TREISMAN, A. Strategies and models of selective attention. Psychological Review, $1969,76,282-299$.

TREISMAN, A. Verbal cues, language, and meaning in selective attention. American Journal of Psychology, 1964, 77, 206-219.

TREISMAN, A., \& GEFFEN, G. Selective attention: Perception or response? Quarterly Joumal of Experimental Psychology, 1967, 19, 1-15. 